\title{
Environmental Factors and Hot Spot Areas of Juvenile Delinquency in Bangkok
}

\author{
Tanet Ketsil*, Mutita Markvichit and Wanwipa Thongsri
}

Faculty of Social Sciences and Humanities, Mahidol University, Thailand

\begin{abstract}
This research surveyed and mapped the juvenile delinquency risk areas in Bangkok, to establish environmental development measures to reduce the risk. This qualitative research was conducted in the Geographic Information System area using surveys of Bangkok Metropolitan Police Divisions 1-9, 36 in-depth interviews with noncommissioned and commissioned police officers and two official seminars. Finally, the research results were used to develop an online map in the Google Maps system. The analysis of the environmental problems of the juvenile delinquency areas' survey map revealed four main juvenile crimes: 1) drugs, 2) property3) assaultand4) motorcycle drag racing; they also identified 30 risks areas most of which were slums, secluded alleys with inadequate lighting, entertainment venues, and convenience stores open 24 hours a day.
\end{abstract}

Keywords: Environmental crime assessment, community crime risk area, juvenile delinquency, policing, crime mapping, Bangkok Thailand.

\section{INTRODUCTION}

Children and juvenile crimes exist in every country across the world. The severity of the crime will be determined by each country's anti-criminal measures. This is also a major issue in Thailand. This can be seen from the statistics report of the Department of Juvenile Observation and Protection, classified by offenses from 2016-2017 as follows:

From the statistics, it can be seen that the highest number of offenses related to narcotic drug crimes is in 2016, 11,559 male cases, 758 female cases; in 2017, 10,232 male cases, 741 female cases; followed by property offenses in 2016, 5,141 male cases, and 376 female cases; in 2017, 4,063 male cases, 277 female cases 277, and offenses relating to life and body in 2016, 3,372 male cases, 320 female cases; In 2017, 2,638 male cases, 241 female cases. Most of these cases occurred in provinces with rapid economic growth, such as in Nakhon Ratchasima, Chonburi, Chiang Mai, Roi Et, Samut Prakan, Pathum Thani, Songkhla, Ubon Ratchathani, Surat Thani, Nakhon Si Thammarat and the capital city of Thailand, Bangkok. If the crime violence ranking is ranked, Bangkok has the highest criminal crimes (Uttaphat 2017).

The highest level of crime severity in Thailand, which the perpetrators surveyed above included juvenile offenses in the Bangkok metropolitan area, which were still considered offenses at a very high

*Address correspondence to this author at the Department of Social Sciences, Faculty of Social Sciences and Humanities, Mahidol University, Salaya, Phutthamonthon, Nakhon Pathom 73170 Thailand; Tel: (66) 089-857-9859; E-mail: tanet.ket@mahidol.ac.th

\#E-mail co-authors: mu_frog@gmail.com and wanwipa002@gmail.com level, as can be seen from the example. There are ongoing arrests of juveniles in drug crimes, robbery, motorcycle races. The key factor in controlling and reducing the long-term offense of children and youth in the Bangkok Metropolitan Area is environmental analysis and control to reduce the risk of crime, as the context and environment may change over time and according to the social context. This is to effectively control the area of risk and cut the cycle and reduce the chances of offenses of children and juvenile in the Bangkok area.

From the past research studies on crime in Bangkok and other provinces, it was found that the study was usually done in the environment that was at risk of crime caused by the act of adults only. For example, the research by Yiewpaisarn (2007), Phutaengpetch (2015), Srithammarong (2016), and Wongpanya (2017) conducted studies on crime area in Bangkok and other provinces. They found that the nature of the crime area most tended to occur in cities with sustained economic expansion and congested communities in which most crimes occurred during the night than in the afternoon.

However, the study of the environment and the area of risk of misconduct of youth in Bangkok Metropolis area has not yet found much research focused on this issue. In addition, the offense rate of children and juvenile is likely to continue to increase. Therefore, the researcher is interested in researching the issue to link past and present problem situations which will lead to more effective solutions to crime caused by the act of both adults and young people from inappropriate environments. 
Table 1: The statistics report of the Department of Juvenile Observation and Protection, classified by offenses from 2016-2017 (Department of Juvenile Observation and Protection, August 2018)

\begin{tabular}{|c|c|c|c|c|}
\hline \multirow{3}{*}{ Offense base (number of cases) } & \multicolumn{4}{|c|}{ Year } \\
\hline & \multicolumn{2}{|c|}{2016} & \multicolumn{2}{|c|}{2017} \\
\hline & Male & Female & Male & Female \\
\hline Offenses relating to narcotics & 11,559 & 758 & 10,232 & 741 \\
\hline Offenses relating to Property & 5,141 & 376 & 4,063 & 277 \\
\hline Offenses relating to life and body & 3,372 & 320 & 2,638 & 241 \\
\hline Offenses relating to weapons and explosives & 1,830 & 30 & 1,375 & 33 \\
\hline Sex offenses & 1,377 & 29 & 1,232 & 34 \\
\hline Offenses relating to peace, freedom, reputation and government & 755 & 74 & 574 & 53 \\
\hline Other offenses & 3,058 & 614 & 2,804 & 463 \\
\hline Total & 27,092 & 2,201 & 22,918 & 1,842 \\
\hline Total number of cases & \multicolumn{2}{|c|}{29,293} & \multicolumn{2}{|c|}{24,760} \\
\hline
\end{tabular}

Therefore, this study focuses on the environmental problems affecting juvenile delinquency by exploring areas with high juvenile offense rates, according to the Interview for local police officers who are experienced in juvenile crimes, together with the statistics of juvenile crimes in the Bangkok area, and application of GIS program technology to create a map identifying the most likely juvenile offense areas for the benefit of analyzing the environmental problems and the risk areas of juvenile offenses, and create measures to improve and develop the environment in areas at risk of offenses of children and youth. This can be used to be a database for the benefit of the analysis, planning, control and significantly reduce the chance of offenses of children and youth in the Bangkok area. In addition, research studies on this subject help to foster a greater understanding of environmental problems and a more widespread analysis of the risk areas affecting the offense of children and youth in Thailand.

\section{LITERATURE REVIEW}

Juvenile delinquency is a phenomenon that includes all the infringements of the social rules committed by young people under 18, breaches the penal sanctioned. It thus involved illegal activities committed by the child or a teenager.

Sellin firstly introduced the concept of deviant from the study of the complex problems of socio-criminoGeneris. Deviants are labelled as the assembly behaviors that are directed against the rules of conduct or against the institutional order. In the next twenty years later, Merton labelled deviant as all the dysfunctional misbehaviors, which threaten the balance of the social system. Simply, juvenile delinquency refers to the behavior of non-adults that violated the rules and regulations set by the government or society. In order to better understanding juvenile delinquency, it is important to define juvenile. Internationally, there is no consensus over the definition of juvenile

In the Thai context, the definition of concepts regarding juvenile delinquency is associated with the law. According to Thai laws, defined 'child' as a person being less than eighteen years of age with the condition that he/she would not have married. Based on the definitions given above, it can simply be concluded that any crime against the law, especially criminal law, committed by children under 18 years old may be classified as juvenile delinquency.

However, many young Thais are flouting the social norms by, for example, disobeying school rules; meeting unlawfully; gathering for organized fights; and being involved in illegal activities such as drug-related offenses, burglary, and assault and battery, many of which are associated with a level of violence similar to adult criminal activities. The following reasons have been identified for these juvenile delinquency problems:

Internal factors caused by physical disabilities: Young people with physical disabilities are often ridiculed by their peers in Thailand, and therefore, to find something to make themselves acceptable to society, they get involved in activities such as gang fights and motorcycle drag racing on the highway. Further, it should be noted that young people in their late teens often 
have less emotional control when making decisions to commit offenses lbid.

(2) External factors such as a broken family, living in slums, poor social environment, illegal assembly in disused gas stations, and visiting entertainment venues focused on sex, which encourages low-life behaviors such as theft, drug abuse, and drag racing Ibid.

Several theories have explained the phenomenon of delinquency and the associated factors.

Sarah Vidal et al. studied Maltreatment, family environment, and social risk factors: Determinants of the child welfare to juvenile justice transition among maltreated children and adolescents. The objective of the research was to study the transition from the child social work system to the youth justice system, with 10,850 children receiving improper care and adolescents. It also looked at risk patterns that included violence and chronicity from improper parenting, hostile family environments, and social risk factors affecting nearly three percent of children the received inappropriate parenting and adolescents receiving firsttime juvenile convictions within an average of six years in dedicated state agency custody. Social risk factors included the child's age, gender, and race (black or Latin America). These can all be predicted to have significant implications for the risks of transitioning to youth justice systems and the association of improper parenting. In conclusion, characteristics of the poor family environment significantly increase the risk of transitioning to the youth justice system. The results of this study were important to a policy to develop and improve systems for children receiving improper care, especially those at risk of transitioning to youth justice systems.

Ryan C. Meldrum studied the association between low self-control biological parents and juvenile offenses. The relationship between parenting, the family environment, and the antisocial behavior of children and young people began to study. The data were collected from the assessments through the juvenile justice system of 101 people residing in the southeastern United States. In addition, the environmental aspects of the family, family ties, family conflicts, and parenting efficacy were considered that result in offending and low self-control children. The episodic analysis found that fathers, mothers, or lowself-control births were associated with a wide range of aspects of the family environment and youth offenses.
The relationship between the low self-control parent, parent, and juvenile misdemeanour and the offense of the youth was intermediate to the family environment. Additional analyzes also suggested that the relationship between a parent, poor self-control parent, and the family environment may be an influencing factor.

\subsection{Hot Spots Policing and Theoretical Underpinnings}

Hot spots policing has become a very popular way for police departments to prevent crime. Crime hotspots have a distinctly spatial nature and accurate identification of hotspots is an important crime prevention tool. While the definition of hotspots varies globally based on the different perspectives, 'hotspot' generally refers to an area that is the target of a higher than expected level of criminal activity.

Hot spots policing is associated with three complementary crime opportunity theories (Eck and Weisburd, 1995): rational choice, routine activities and environmental criminology (Braga et al., 2012). The rational choice perspective assumes that "offenders seek to benefit themselves by their criminal behavior; that the involves the making of decision and choices, however rudimentary on occasion these choices may be; and that these processes, constrained as they are by time, the offender's cognitive abilities, and by the availability of relevant information, exhibited limited rather than normative rationality (Cornish and Clarke, 1987) Routine activities theory posted that a criminal act occurs when a likely offender converges in space and time with a suitable target (e.g. victim or property) in the absence of a capable guardian Cohen and Felson, 1979) Rational offenders come across criminal opportunities as they go about their daily routines and make decisions whether to commit offenses. The assumption is that, if victims and offenders are prevented from converging in space and time through the effective manipulation of the situations and settings that give rise to criminal opportunities, the meaning of police can reduce crime.

In 1942, Shaw and McKay studied the environmental crime statistics from the Chicago Juvenile Court and published their work, titled Juvenile Delinquency and Urban Areas, in which they divided Chicago into five districts: District 1, which was economic; District 2, which was a district of mainly degenerating changes and was typically residential areas with small businesses and low-priced rental 
homes interspersed with pawnshops, low-priced bars, and other low-grade entertainment; that is, this district was slum-like with mainly minority residents; District 3 , which was the industrial factory area in which many workers lived; District 4 , which was a middle-class to upper-middle-class suburban residential area; and District 5 which was a suburban area for both private and public transportation to transfer goods to the working center of the city. Shaw and McKay's studies on the juvenile delinquency rate relationships found that juvenile delinquency was higher in the slum and business districts, especially in districts going through changes such as those with low-priced rental homes near downtown with the crime rates decreasing further from the city center.

Heinze et al. noted that insufficient monitoring in the community is connected to an extremely unpleasant feeling in residents. Criminal activities were conducted in abandoned lots with overgrown grass and inadequate light. The study concluded that routine monitoring by community members can reduce illicit activities and crime in the community. Similarly, (Schellenberg et al., 2018) concluded that the sense of community belonging is associated with building strong relations in the community. Community members are involved in the maintenance of community such as the building of environment and perception of crime. (Piscitelli A, 2019) supports the core finding of Shaw and McKay and notes that social disorganization corresponds with the crime rate. (Levesque M, 2020) illustrated that several factors may be responsible for juvenile delinquency, and the general strain theory can assist in understanding juvenile delinquency.

Environmental criminology explores the distribution and interaction of targets, offenders, and opportunities across time and space understanding the characteristics of places, such as the presence of crime attractors or crime generators, is important as these attributes give rise to the opportunities that rational offenders will encounter during their routine's activities (Brantingham and Brantingham, 1991). Although this perspective is primarily concerned with applied crime prevention, Weisburd et al. suggest 'environmental criminology's basic contribution lay in its call for a change in the unit of analysis from persons to places'. The attributes of a place are viewed as key in explaining clusters of criminal events. For example, a poorly lit street corner with an abandoned building is the golden place for a drug market. The lack of proper lighting, an abundance of mass locations around the derelict property, a steady flow of potential customers on the thoroughfare and a lack of informal social control at the place caused attractive opportunity for drug sellers. In many such cases, the police spend considerable time and effort arresting sellers without noticeably impacting the drug trade. The compelling criminal opportunities at the place attract sellers and buyers and thus sustain the market. If the police want to be more efficient at disrupting the market, this suggests they should focus on the features of the place which cause the drug dealing with cluster at the particular location such as the studies of (Green L, 1996).

Wilson and Kelling 1982 compared community housing conditions and found that when houses with broken windows were not repaired, and there were no environmental controls in the community, more windows would be broken, and there would be a larger number of offenses as it would be assumed that nobody was paying attention to the public environment. This concept led to the Broken Window Theory that has since been applied to assess community environmental conditions.

Therefore, as exemplified in these two previous studies, the community environment and the occurrence of crime appear to be inextricably linked; that is, if the community environment is disordered, then the disorder intensifies; if there is no motivation for the community to return to a state of order, this increasing disorder can lead to increasing crimes. Moreover, if the community continues to ignore public order, community order will deteriorate. Even good families who care for their children and seek redress against those who create the disorder will be unable to maintain order, if not assisted by community action. Consequently, as these environments become desolate without a caretaker, good people move out, and the gathering of the indolent young increases. When the adults in the community have no regard for monitoring inappropriate behaviors of the adolescents, there is an inevitable increase in crimes such as robbery, larceny, fighting in public and drug abuse and drug dealing.

All of this indicates that the reaction (or nonreaction) of the people in low social status communities creates an environment for crime with disorderly communities tending to have higher crime rates than those in others. Therefore, mapping such environments could give useful guidance on the development of methods for controlling and reducing crime in the area. 


\subsection{Juvenile Crime Hot Spot Areas: The Lack of Thai Policing Analysis}

Technology and computer systems play an important role in crime hotspot areas creation and become the essential part of this analyzing process with the evidence of many police agencies have extended the drive-in information technology to include GIS.

By using GIS, the police have the ability to map and analyze the spatial distribution of crime and can reveal patterns of criminal activity that would not otherwise be apparent through more traditional means. GIS also gives police the ability to manage hot spots policing. Hot spots policing is associated with small but meaningful reductions in crime at locations where criminal activities are most concentrated. Focusing police efforts that targeted high-activity crime 'place' rather than large areas such as neighborhoods.

Research studies have explored the utilization of GIS technology in crime analysis. Pankaew P, 2010 studied criminal data analysis using a geographic program. The results of the study found that the crime map program was able to identify areas, sub-districts, districts, and provinces by selecting the crime data collected in the Royal Thai Police. This can be displayed on a crime map, analyze crime types in each area, and analyze crime statistics for each time period. Relationships were then sought to establish appropriate checkpoints at the appropriate times that police officers should inspect crime-prone areas to reduce crime in that area.

Suriyachay N, 2010 studied the development of a crime map system, a case study of theft in the area of Muang District, Nakhon Pathom Province. The results of the study showed that the development of the system can make: 1) A map showing the density of car theft that in Phra Pathom Chedi Sub-district there were the most car thefts in 26 cases. 2) The most stolen vehicle types were motorcycles, with a maximum of 69 cases. 3) The manufacturer (brand) of the car that was most stolen was Honda (47 cases). 4) The period from 20.00 to 21.00 was the time of the most theft of 10 cases. In this development, there was a limitation in accessing the system because it must be connected to the internet at all times. Therefore, the faster or slow system usage depended on the speed of the internet signal.

Chanrup N, 2012 studied the problem of solving the recidivism in drug cases among youths in the Child and
Youth Training Center Area 7, Chiang Mai Province, found that the causes and problems of recidivism of children and youth in Child and Youth Training Center Area 7, Chiang Mai Province, caused by external factors such as community context, social pressures, and the surrounding environment of children and young people. This was because the offending children and young people live in unsuitable communities or areas such as areas with high offense rates, mingling sites, and drug trafficking sites. Occupations of families, fathers, mothers, or parents of children and young people were mostly seasonal, and there were some with uncertain occupations that led to most children and young people to neglect children, rarely strict, or severe punishments.

Phuthangphet studied the areas at risk of car and motorcycle theft in Muang District, Phitsanulok Province. The result of the study has shown that current car and motorcycle theft occurred in large numbers and was difficult to track down, so prevention planning was something that should be of interest. Using maps to describe areas of theft congestion was another way to support the decision-making process of police officers to plan to prevent theft. The map was presented as an area of high theft incidence and used a Kernel Density Estimation method, which was one of the effective methods of estimating crime density. Data analysis and visualization have applied GIS and selected a tool called Kernel Density to locate areas of the mass car and motorcycle theft (hotspot) using crime data from 2010-2014 that happened in the area of responsibility of Muang Phitsanulok Police Station, with a total of 785 cases. The study found that most of the theft-prone areas were populated residential areas and nighttime incidents. The most stolen cars were Toyota. The most stolen motorcycles were the Honda brand.

\subsection{Bangkok: The Land of High Crime Committing and Crime Hot Spot Areas Analysis}

Bangkok, the capital of Thailand, has a rapidly expanding urban area and is the center of government, the commercial center of the country, and a popular destination for tourists, with hotels, guesthouses and entertainment facilities located across the city Utaphat. Consequently, Bangkok is a highly urbanized city, with many people continuously immigrating to the city to look for work lbid. Therefore, as many different ethnicities are living in the capital city, there is little social cohesion, which means that the severity of the 
crime is significantly higher than that in the other Thai rural areas Ibid.

Using the Technique for Order Preference by Similarity to the Ideal Solution (TOPSIS), Utaphat developed a Crime Severity Map of Thailand based on crime severity in Thailand in 2017, which found that Bangkok had the worst crime levels in the country, primarily because of the dense population, the industrial concentration, and a large number of tourist attractions. This analysis also found that another reason for the high crime rate in Bangkok was the significant juvenile delinquency, with many young people being arrested on drugs, robbery, and drag racing charges. Therefore, it is important that the relevant government agencies develop measures to control and ultimately prevent juvenile delinquency. However, doing this requires an analysis of the juvenile delinquency environments and risk areas, the results of which would provide effective guidance to control the risk areas and reduce the possibility of juvenile offending in Bangkok.

Tititampruk D, 2016 concluded that burglary was a violation of privacy and also caused considerable fear; however, most burglary research has been in Western countries (Chiew et al., 2020) with comparative studies in areas that have different social-cultural contexts being few. Tititampruk's study drew on rational decision-making processes to estimate the costs and benefits of committing a given crime with two central questions guiding the study: what are the thoughts of the Thai offenders when deciding whether to commit a crime, and how do they choose their specific targets? The study sought to answer these questions using data from interviews with incarcerated residential burglars in Thailand collected primarily through semi-structured interviews with 45 Thai inmates convicted of a residential burglary at some point in their criminal careers and incarcerated in a federal and local correctional institution around Bangkok.

The interviewees were asked about their own experiences in committing burglaries, including those in which they had wanted to commit burglary but chose not to do so. The interviewees were asked to complete a map task to clarify the locations of their targets on a Bangkok map. Therefore, the central focus of Tititampruk's study was to elucidate the offenders' target selection, methodologies and methods used to identify suitable residential burglary targets. Special attention was given to the extent to which the offenders utilized rational processes to select their potential burglary targets, and the environmental conditions and features they used as discriminative cues.

However, the findings of Tititampruk's study should be interpreted carefully because of the relatively small sample size. The study data analysis indicated that both the risks and the rewards of residential burglary influenced the burglars' target selections. However, when assessing residential burglary targets, the burglars were found to be significantly more influenced by the environmental cues related to risk than by the cues related to reward with most being highly aware of the various residential burglary prevention measures such as burglar alarms, neighborhood watch, dogs and signs of repeat victimization.

Tititampruk's key findings relate to cultural differences in burglars' target selections and decisionmaking during the burglary process. For example, most burglars believed in fate and luck when they decided to commit burglary with gender and age both affecting the residential burglars' decision making about target selection and crime commission. Based on the findings of Tititampruk, guidelines for the development of residential burglary prevention initiatives and measures, such as increasing police patrols, developing job training programs inside prison, and establishing neighborhood watch programs were recommended.

Sahaphatthana P, 2009 has studied research on a project for area analysis with a high volume of burglary cases in Bangkok. This research used the Geographic Information System (GIS) program to identify areas where crimes are more common (hot spots). The results of the study showed that the areas where there was a large number of burglary events would look as follows: 1) It was an area that utilizes a mixed space in the same area, was a coexistence of people with differences in status, social status, race, and environmental, physical and social degradation, as well as not having enough knowledge to protect themselves from being a victim of burglary. For measures to prevent burglary, there should be a patrol system to work in a proactive manner, educating and creating behaviors for the people to protect themselves so as not to become victims of criminals. Community people should be encouraged to join forces to prevent crime and to develop physical and social environments to reduce the risk of burglary.

Yeampaisan studied crime spatial density, a case study of Phra Nakhon District, Bangkok, based on the 
kernel model. The results of the study found that the spatial distribution patterns of crimes classified according to the type of offense had different types of incidents depending on the circumstances of the crime. It was found that drug cases, burglary cases, and suicide cases were most common in public areas and blind spots at night, such as Sanam Luang, the ferry pier under Somdej Phra Pinklao Bridge, Phra Nakhon side, Santichai Prakan Park. etc. Assault cases and suicide cases were concentrated in the entertainment areas such as Khao San Road, Tanao Road, and Chakrapong Road. The distribution of cases that took place during the day had a different pattern of prosecution from the night, which was often concentrated in crowded and prone places such as on the sidewalk along Ratchadamnoen Road, in front of the Government Lottery Division, and in the area of Bang Lam Phu market, which most them were burglary and property grab and run cases. The dense crime scene continued to be concentrated in the same area that occurred each year. The assessment of high crime risk areas clustered in three key areas: Sanam Luang area, Khao San Road, and the ferry pier under Somdej Phra Pinklao Bridge which was a highly concentrated area of cases. This crime-prone area map can be used to effectively plan, prevent, remedy, and reduce the severity of crime in the Bangkok area. For example, patrols made police can enter the area more quickly, can assess crime in the area more easily, and can be used to level the responsibility of the executive officer for planning crime mitigation locally, making it easier to visualize the prosecution leading to a reduction in the number of crimes in one way.

Srithamarong studied crime risk area assessment by analyzing spatial statistics. The researcher used the Geographic Information System program to study the spatial relationship of burglary incidents in Ban Pong District, Ratchaburi Province. The results of the study showed that the areas at risk of burglary incidents were Ban Pong Sub-district, Nong Or Sub-district, and ThaPha Sub-district. The area that had the most birth was Ban Pong Subdistrict because it was a center of trade and was also a community with great economic and social prosperity, resulting in a large number of immigrant populations like the ThaPha Sub-district. Nong Or Sub-district was considered an important industrial complex, such as the largest bus terminal in Thailand and the largest beautiful fish market in ASEAN, resulting in large numbers of non-immigrant populations or travel to work. When there was a large number of foreign populations joining together, there was an increase in cultural and social diversity. As people had different cultures and livelihoods, they were at high risk of different types of crimes, consistent with the study of population-based physical factors. It was found that high incidence areas would occur in regions with moderate to high population densities and in landuse areas, agricultural areas, buildings, and communities. The three-year burglary incidents spread eastward, covering the central area of Ban Pong district, making it possible to predict that future incidents were likely to go east of the study area into Nakhon Pathom Province.

Kenwan A, 2018 studied personal factors, parenting characteristics, association with deviant peers, and self-control influencing juvenile drug offenses with the cases of the Juvenile and Family Court, Sakon Nakhon Province. The research results showed that 1) Personal factors: The majority of the sample were male, aged 13-17 years, and all of whom had taken drugs. The most addictive drug was methamphetamine, taken for a period of 1-6 months. The frequency of use was approximately 2 times a week. 2) Parenting factors were found that the subjects were reared in descending average order that were uncontrolled parenting, punitive, rational, and supportive. 3) The peer fellowship factors with deviant behaviors were found that the percentage of subjects had a descending friendship. These included friends who take drugs, friends who like to hang out at night, friends who have run away from school, friends who don't study, friends who don't work, and friends who have been arrested for wrongdoing or prosecuted. 4) The self-control factor found that the sample group had self-control characteristics in descending average order, namely the physical activity element, the simple and simple work element, the impulsive element, and the risk element. 5) Factors that could be used to predict the offenses of drug offenses among juveniles were statistically significant at the .05 level, namely parenting factor and peer association factors with deviant behavior.

Wongpanya studied the application of GIS to analyze the density of car theft cases in Nakhon Pathom Province. The data of the crime of car theft in Nakhon Pathom Province from 2013-2015 by the Provincial Police Area 7 were used for the analysis. The geographic information system was used to create crime databases, then identifying the crime scene and analyzing the vulnerable areas. Analysis was divided 
into two types: 1) crime density analysis 2) analysis of the timing of the crime, which consisted of two periods: daytime and night time. The study found that the areas with the greatest number of car theft were residential areas, urban areas, areas with high population density. The most crime scene was nighttime. The crime map was one of the important tools that the relevant authorities should be able to leverage in their mission to make the work of preventing and suppressing crime more effective.

From the literature review and related research, the research team has applied in determining the study and research guidelines, environment and the risk area of offense of children and youth in Bangkok area. The research started with studying juvenile offense patterns such as drug cases, property cases, life and body cases, and motorcycle racing cases. In addition, the researchers explored areas and contexts to analyze the juvenile offense environment, which provided information on the risk areas and map the offense risk areas for children and young people to create preventive and corrective measures and solutions to reduce the problem of risk areas in the offense of children and young people.

\section{METHODOLOGY}

\subsection{Gathering Information}

Data on environmental factors and risk areas of juvenile delinquency were obtained from academic journals, textbooks, thesis dissertations, and documentaries such as juvenile criminal cases and cases studies. The researcher also reviewed statistics for areas in Bangkok with the highest juvenile delinquency in the last four years (2015-2018) in the 1-9 Metropolitan Police Division.

\subsection{Research Instruments}

This research employed area surveys using GIS, indepth interviews, brainstorming seminar, and the development of an online map in the Google Maps system.

\subsection{Collecting Data}

\subsubsection{Area Surveys using GIS}

Statistics for areas in Bangkok with the highest juvenile delinquency in the past 4 years (2015-2018) were collected from police stations in the 1-9 Metropolitan Police Divisions, after which GIS was applied to map the highest-risk environments in coordination with local police. The most serious areas of juvenile delinquency in the 1-9 Metropolitan Police Division are indicated in Table 2.

\subsubsection{In-Depth Interviews}

Using a purposive sampling method, 36 in-depth interviews with non-commissioned and commissioned police officers in the police districts that had the most serious juvenile delinquency were conducted. The questionnaire had three parts. The first section was general information on key informants such as gender, age, and position. The next part included questions on the characteristics, patterns, factors and risk areas of juvenile delinquency. The final section comprised development guidelines and measures to reduce the risk areas of juvenile delinquency. The in-depth interview strictly followed the regulation of ethical reinforcement of human research. Before the interview, the researcher explained all the questions to the key informants and informed them that the interviews were being recorded. The interviews lasted for around two hours. Data from the in-depth interview were later inspected in the first brainstorming seminar.

Table 2: Highest Number of Juvenile Delinquencies in the 1-9 Metropolitan Police Division in Bangkok

\begin{tabular}{|c|c|}
\hline Metropolitan Police Division & The highest number of juvenile delinquency cases \\
\hline \hline 1 & Din Daeng Metropolitan Police Station \\
\hline 2 & Bang Khen Metropolitan Police Station \\
\hline 3 & Rom Klao Metropolitan Police Station \\
\hline 4 & Prawat Metropolitan Police Station \\
\hline 5 & Thong Lor Metropolitan Police Station \\
\hline 6 & Yannawa Metropolitan Police Station \\
\hline 7 & ThaPhra Metropolitan Police Station \\
\hline 8 & Talat Phul Metropolitan Police Station \\
\hline 9 & Phetchakasem Metropolitan Police Station \\
\hline
\end{tabular}




\subsubsection{The Number of INFORMANTS}

\section{(1) In-Depth Interview}

An in-depth interview was conducted using purposive sampling of 36 persons, consisting of:

Police officers at an operational level under the Metropolitan Police Division 1-9, 2 officers for each division, totalling 18 officers

(2) Police officers at the executive level, from the superintendent, under the Metropolitan Police Division 1-9, 2 officers for each division, totalling 18 officers.

\section{(2) Organizing a Seminar and Brainstorming}

Police officers under the Metropolitan Police Division 1-9, 2 officers for each division, totalling 18 officers, 10 criminology professors and academics, totalling 28 people. The first brainstorming seminar was held in Bangkok in April 2019 to check and correct data from the in-depth interviews. Additionally, the brainstormed included solving problems related to the factors behind and risk areas of juvenile delinquency. The second brainstorming seminar was held in Bangkok in May 2019 to analyze data before presenting them to experts.

\subsection{Quality Testing of Research Instruments}

Tools were designed to inspect, edit, and improve the interview forms and a seminar to determine specific ideas. Five experts, a criminologist, a justice administrator, two GIS experts and an expert in social sciences and the environment, inspected the tools for content validity in terms of language usage, content coverage and consistency. The questionnaire was developed to have an index of the item-objective congruence (IOC) from 0.50 up, and based on the expert opinions and brainstorming before the data collection, questions were added.

\subsection{Research Ethics}

This research met all ethical requirements for human studies defined by the university and was certified by the Faculty of Social Sciences and Humanities, at Mahidol University (certificate no. 2018/294.2512). Items in the in-depth interviews and the brainstorming seminar issues were reviewed by committees to be in accordance with the research principles and international standards. During data collection, official letters were sent to our sample department to obtain the necessary permission. On the day of the interview, the researcher read the consent form and asked for interviewees' signatures.

\subsection{Data Analysis}

To ensure complete interview information, the investigator asked permission from the interviewee to tape the interview and take notes. Interview questions will help answer research questions by providing complete and accurate insights into interpretation regarding the characteristics, patterns, factors and risk areas of juvenile delinquency including the development of guidelines and measures to reduce the risk areas of juvenile delinquency. After completing data collection, the investigator can analyze the data using the NVIVO program for analysis, with interviews and data analysis conducted through a qualitative analysis method. The conclusions drawn from the study were shown to the interviewees for review and verification of their accuracy.

\subsection{Creation of Online Map}

Data from the in-depth interviews and brainstorming seminar were used to create an online map. The online map was developed from satellite photos in the Google Maps system to show the location of the environment and identify specific information, such as juvenile delinquency risk locations, the surrounding environment important landmarks, and road network routes, and risk area. A database was developed containing information about the situation, the type and level of risk, and crime perpetration times in each risk location that could be applied to the map and downloaded as an image (JPG) file.

\section{RESULTS}

\subsection{Environmental Problem in the Risk of Children and Juvenile Crime}

From a synthesis of interview results from 36 police officers including brainstorming seminars from police officers, university officers and scholars, totalling 28 people commented that most of the environmental problems in the areas that are at risk of children and juvenile crime can be divided into 4 cases of children and youth in the Bangkok area: 1) drug-related cases, 2) property-related cases, 3) life and body cases, and 4) motorcycle racing cases. This is consistent with the statistics of the Department of Juvenile Observation and Protection from 2016-2017. It was found that the highest number of offenses relating to drugs, followed by property offense, criminal cases relating to life and 
body and motorcycle racing cases, which can summarize the cause of each case are as follows.

1) Drug-related cases: The analysis of interview data from a sample of 36 people found that ten of the police officers had identified environmental factors that affect juvenile offenses, stating that the problem of offenses of Childrens and juvenile in Bangkok was born from weak family institutions, lack of care and attention from their family members. In addition, children at this age would enter adolescence, which was the age full of curiosity. When solicited or challenged by a friend, it was easy for children to enter the field of drug addiction. Moreover, the urbanization of Bangkok has made the character of the people living in the area isolated. Most crime scenes were not accessible due to the fact that they were isolated area, inadequate lighting and no surveillance cameras. This is reflected from the example of an interview with a police officer who mentioned this issue as follows:

"The beginning of drug addiction is smoking. And the children to be on the lookout for are those who do not want to study. When parents send them to study, they often fled to mingle, smoking in the confined corners of the mall." (CHPO06)

"Most of the children who use drugs come with their parents to work. They are children outside the area, such as contractors, most of them are construction workers' children. Some of these families are foreigners. Children who have drug addiction problem often are out of school." (PO06)

The results of this study are consistent with Treeros (2010) and Puranapanya (2015) research, which found that factors affecting the offense of drug offenses among children and youth are Family parenting factors, divorced parents, lack of time for close supervision of their children, as well as curiosity, as they are, mostly are persuaded to try drugs.

While the remainder of the sample did not identify environmental factors affecting juvenile delinquency, but did identify the offending patterns and nature of children's drug involvement. More than half of the respondents said that the vast majority of children and young people perpetrated in drug-related crimes were drug users, local retail traders, starting with being drug deliverers. After that, the drug was tried until they became both drug dealers and a drug user at the same time. Children and juvenile were exposed to drugs from adults as intermediaries, bringing drugs to the community where they live.

2) Property-related cases: The analysis of interview data from a sample of 36 people found that most of the 34 police officers commented in the same direction that the nature of juvenile offenses was a characteristic of small cravings and burglary, common robbery in convenience stores, shopping malls and in residential areas in alleyways in isolated, overgrown communities, with inadequate lighting as opportunities allow. They may use a moment when people were not careful. The schemes of the offense were not pre-prepared or organized as a team. In addition, there was also motorcycle theft in the basement of a large number of motorcycles parked for driving, which was an individual offense, not a group or a movement in any way. This is reflected from the example of an interview with a police officer who mentioned this issue as follows:

\section{"Most burglaries are motorcycles, convenience store items, or money in some noodle shops or grocery stores." (CHPO02)}
"In most areas, children use robbery methods using timing when the owner of the property accidentally or roughly does not turn off the engine." (CHPO02).

This is consistent with the research of Chidchai (2015) found that the reason why children and young people steal motorcycles because they want to take motorcycles to ride and play, as well as taken for sale or bring some auto parts to decorate their own motorbike. On the other hand, the remaining two respondents gave a different opinion that cases of juvenile stealing property were rarely found in the area where they were responsible.

3) Life and body cases: The analysis of interview data from a sample of 36 people found that the majority of the 32 police officers commented in the same direction that the causes of life and physical crimes arising from juveniles and fights each other or physically hurt each other due to personal problems, or in some cases, the intoxication of drinking resulted in brawls and physical assaults among friends. There were also fight raising among the youths between the institutions. Before the brawl, the student group was preparing to hide weapons such as long-handled knives, guns, pens, in dwelling houses, motel rooms, 
rent houses, or in some cases hidden in the dense bushes at the bus stop, in front of the department store and along Petchkasem Road. This is reflected from the example of an interview with a police officer who mentioned this issue as follows:

\section{"...Most of the problems of the student group are caused by the persuasion of the seniors or inciting the younger generation to fight against the opponents of different institutions." (CHPO07)}

"Important days of the institute, such as the foundation day is an important day for the police to be extra vigilant as it will be the day of the most frequent fighting incidents." (PO07).

This is consistent with the research of Songkiatkul (2017) found that the reason for the controversy among vocational students was due to personal or internal factors, including lack of emotional maturity, lack of self-discipline, misuse of thinking about beliefs and values on the issue of institutional dignity. The remaining 4 people commented that the first two people commented that there were many educational institutes in the area, but in the past, there had been no cases involving a group of children and adolescents fighting, and the other two said that the cause of most cases involving life and body in the area was caused by adulterous problems, arguing for lovers, and the dislike of each group of children within the community itself.

4) Motorcycle racing cases: The analysis of interview data from a sample of 36 people found that most of the 32 police officers commented in the same direction that motorcycle racing cases were caused by imitation behavior and the need for acceptance from a group of friends as well as compete for gambling. Motorcycle races will be arranged by means of communication via Facebook or Line group, which will be a network of motorcycle racing groups where children and youth are popular to compete in motorcycle racing in the area that is a long, straight, non-winding road, complete road conditions without traffic obstructions.

This is reflected from the example of an interview from a police officer who mentioned this issue as follows:

"Youngsters who like to compete with speed will arrange to compete during the holidays from 1:00 am onwards until around 3.00 am.." (CHPOO8)

"In the territories, there were many gathering spots for children. Most of them will gradually meet at different points, about 10 or more motorcycles per point, and then ride straight to the actual race point...."(CHPOO8)

This is consistent with Palwiraphat (2008) research which found that most of the crimes committed were fun. This includes following a peer group in order to gain the respect of their peers, and in some cases even gambling with organizers, outside promoters. On the other hand, the remaining eighteen respondents gave a different opinion that no motorcycle racing cases were found in their respective areas since there are only small roads in their area, children and youth are not interested in competing in speed races in this area.

\subsection{Creating a Risk Point Map}

The creation of a map of the offenses of children and juvenile in all four cases in the Bangkok Metropolitan Area is a map from surveying risk points in collaboration with the operational police in the area where the highest risk is occurring, such as a drugrelated case in the area in which the risk point is at the Din Daeng Police Station, the point of risk in the incident area is an 8-storey flat. For the cases concerning properties, the risk point is at the Yannawa Police Station, which the risk point at which the accident occurred is Soi Narathiwas Ratchanakarin 10. For life and body cases, the risk point is at Prawet Police Station, and the area where the risk occurred is in front of the lam Sombat Market. The case related to the motorcycle race, Bang Khen Police Station, the risky point of the accident is Theprak Road. When the risk point is known, the risk point coordinates are recorded using the Global Positioning System (GPS) on the smartphone, which is a numerical record. After that, data recorded in the field will be converted to coordinates using Geographic Information System (GIS) to determine the reference point on the earth and converting from numerical data to spatial data by using point-type symbols to display data of the risk point areas and set them to display in the format of Map Online.

As shown in Figure 1, the risk areas with the most common juvenile drug-related cases are as follows: (1) the parking area in Soi Chaeng Watthana 4, 


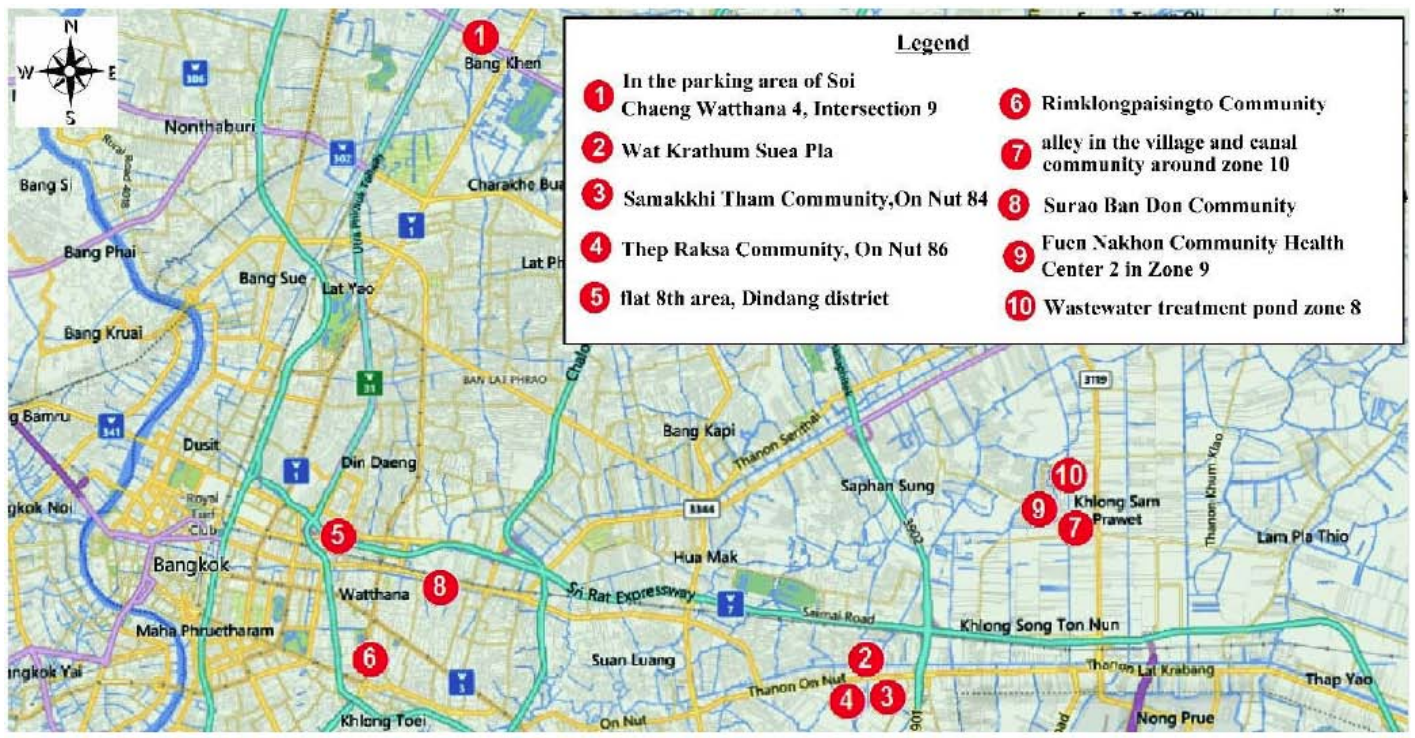

Figure 1: Map of risk areas with the most common juvenile drug-related case

Intersection 9; (2) Wat Krathum Suea Pla; (3) Samakkhi Tham Community, On Nut 84; (4) ThepRaksa Community, On Nut 86; (5) Flat Number 8 in Dindang District Areas; (6) Rimklongpaising to Community; (7) the alley in the village and canal community around Zone 10; (8) Surao Ban Don Community; (9) Fuen Nakhon Community Health Center 2 in Zone 9; and (10) the wastewater treatment pond in Zone 8.

As shown in Figure 2, the risk areas with the most common juvenile property-related cases are as follows: 1) at the bus stop at the Phatthanakan Road Intersection; 2) Wannotai Community, Klong Toey District; 3) Saen Sabai Community, Klong Toey District;
4) behind SurasakMontri School; 5) SoiVibhavadi Rangsit 2; 6) Vibhavadi Rangsit Forest Park; 7) the curvature of ArkhanSongkhro in front of Kuson Thong Community; 8) Soi Naradhiwas Rajanagarindra; 9) under the Bang Phai U-turn bridge; and 10) under the Naowa-chamnian bridge.

Figure 3 indicates that the risk areas with the most common juvenile physical violence cases are as follows: (1) the bus stop in front of lamSombat Market; (2) the area near SoiKanchanaphisek 0010 Kanchanaphisek Road; (3) the bus stop in front of Krung Thai Bank, SoiPhetkasem 65; (4) areas used for hiding weapons, i.e., curvature and William Community; and (5) SoiNoi Na, Kanchanaphisek Road.

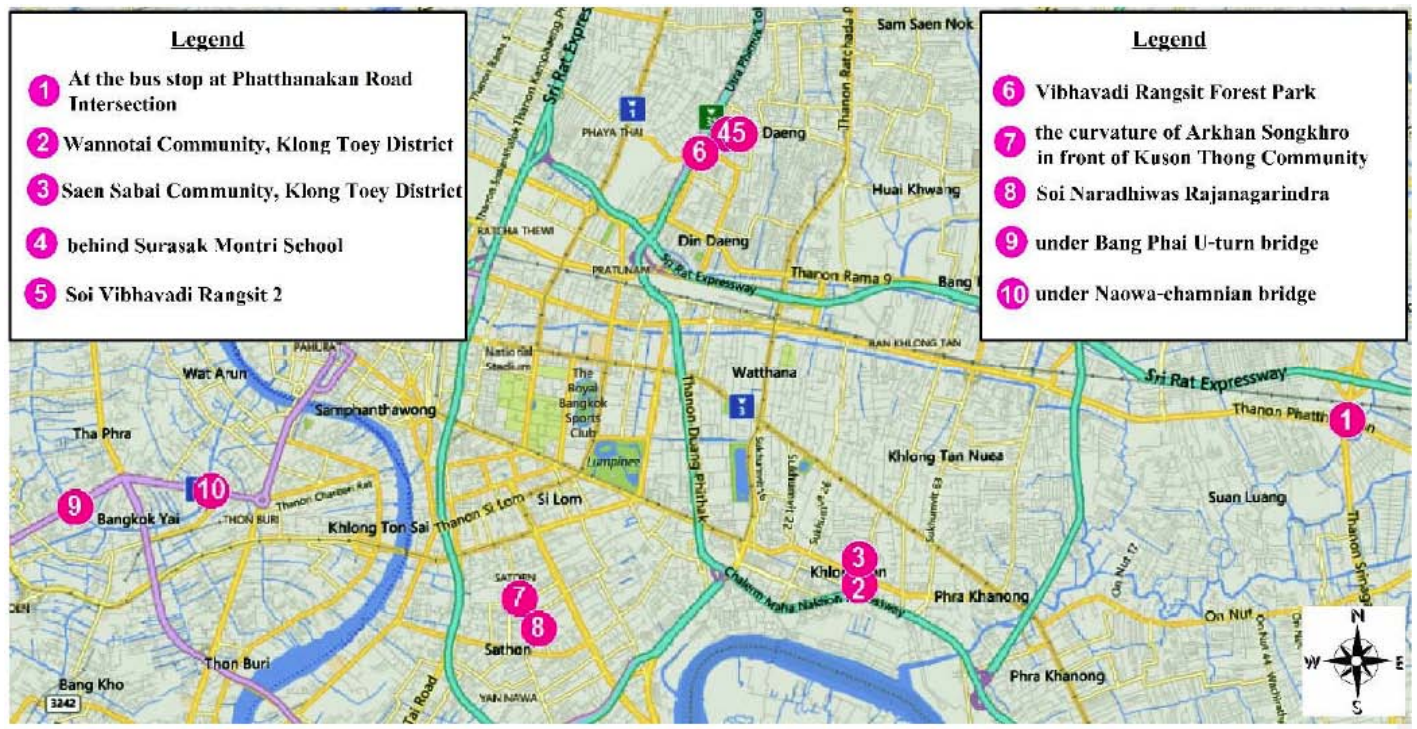

Figure 2: Map of the risk areas with the most common juvenile property-related cases. 


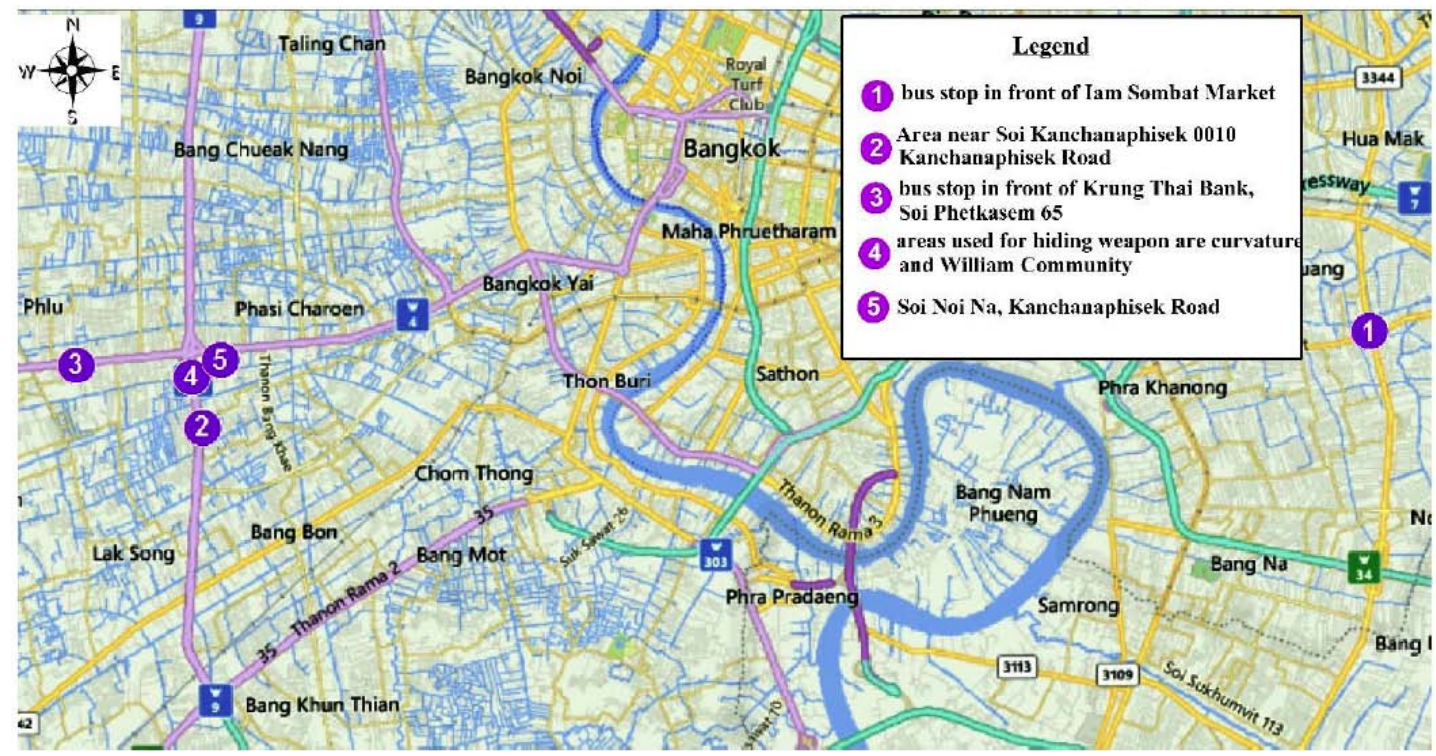

Figure 3: Map of the risk areas with the most common juvenile physical violence cases.

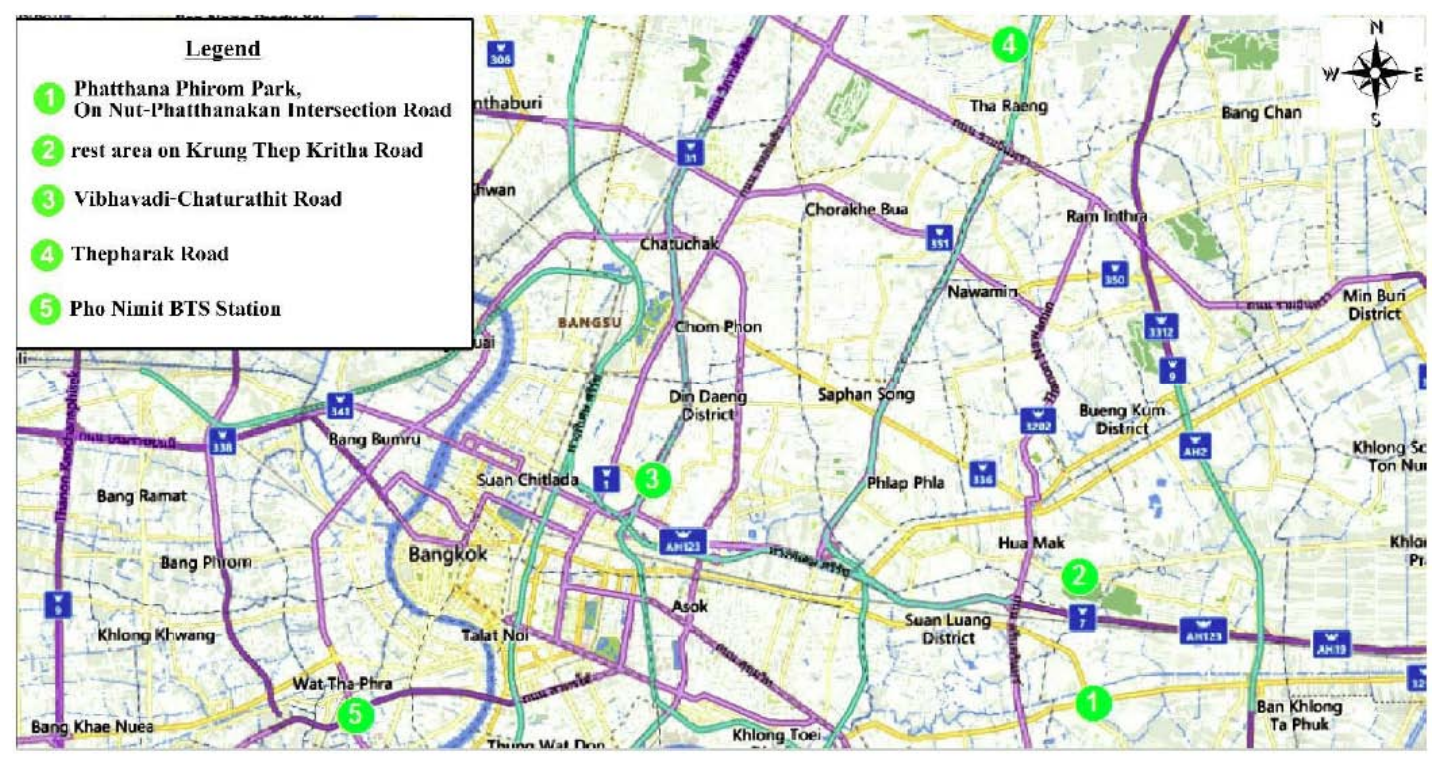

Figure 4: Map of the risk areas with the most common juvenile motorcycle drag racing cases.

As shown in Figure 4, the results reveal the risk areas with the most common juvenile motorcycle drag racing cases are as follows:(1) Phatthana Phirom Park, On Nut-Phatthanakan Intersection Road; (2) the rest area on Krung ThepKritha Road; (3) VibhavadiChaturathit Road; and (4) Thepharak Road (5) Pho Nimit BTS Station.

\subsection{Measures to Prevent and Suppress Juvenile Delinquency in Bangkok}

Measures to prevent or suppress juvenile delinquency, develop the environment, and reduce the juvenile delinquency risk areas in Bangkok are summarized as follows.

\subsubsection{Measures to Prevent and Suppress Juvenile Delinquency in Bangkok}

\section{(a) Police and Volunteer Monitoring}

It was recommended that additional police officers be available to (1) monitor juvenile behaviors and (2) patrol and control establishments that contribute to juvenile delinquency

i. Monitor juvenile behaviors

Police officers need to set up checkpoints to intercept juveniles at risk of offending, especially 22.00 onward. Tee-Wong-Su-Ra' measure to restrain juveniles from meeting in large groups should be 
enforced. Suspicious juvenile behavior must be intercepted and the offenders should be sent home to reduce criminal activities.

ii. Patrol and control the establishments that contribute to juvenile delinquency

Police officers need to patrol risky areas such as spare parts shops or repair shops by recording every motorcycle repair shop in the area, which would reduce the possibility of the young people modifying their motorcycle engines and racing on public roads. Measures should be introduced to investigate drug stores illegally selling drugs such as Tramadol and Procodyl to juveniles.

(b) Projects to Prevent and Suppress Juvenile Delinquency

To prevent and suppress juvenile delinquency, programs such as Thailand's Drug Abuse Resistance Education (D.A.R.E) should provide police officers to educate students, teachers, parents and communities and request their co-operation in monitoring juveniles and supporting the police in identifying risky drugrelated behavior.

\section{(c) Co-Ordinate and Request Community Co-Operation}

It is important that the relevant agencies co-operate with all community sectors and the Royal Thai Police on concrete drug operations and that the police at the local station work with the local community in projects such as the 'White Community' and 'PracharatRuam Jai' projects.

\subsubsection{Reduce the Number of Juvenile Delinquency Risk Areas in Bangkok}

(a) Integrating and Adjusting the Landscape

i. Local police stations should publicize crime risk areas to raise the awareness and surveillance of them by the general public. For example, in secluded alleys, police officers can put up warning signs or police station phone numbers for victims or witnesses.

ii. Day and night high-quality CCTV coverage is needed in risk areas such as alleys and lanes for people to easily identify offenders.

iii. Lighting should be improved, especially in crime risk areas, and be regularly maintained to ensure the safety of people's lives and property.

\section{(b) Community Networks}

i. Local police stations should co-ordinate and develop community networks in high-risk areas, with network members coming from apartments, dormitories, and local businesses and cooperating with the police by reporting suspicious behaviors. Community police education should also be implemented to persuade the general public of benefits of co-operating with the government.

ii. Local police stations should ask the private sector, shops, convenience stores, department stores, agencies and the general public to install CCTV in their premises for them to easily identify crimes and for CCTV to act as a deterrent; these cameras should be installed at the eye level to clearly capture features of the offenders.

iii. Local police, community leaders and Bangkok officials should meet regularly to discuss other methods that could be used to reduce crime in the risk areas.

\section{DISCUSSION}

The results of the in-depth interviews and the area survey in Metropolitan Police Divisions 1-9 identified the main juvenile delinquency risk areas in Bangkok. From the survey and analysis of environmental problems that are risk areas for juvenile offenses in Bangkok, 30 highest risk areas for the most cases, categorized by case type and offense pattern of children and juvenile in 4 cases, including: 1) Cases related to drugs, 2) Cases related to property, 3) Cases related to life and body, and 4) Cases related to motorcycle racing. For example, as in the following table.

From the survey and analysis of the aforementioned environmental problems, it led to the creation of a mapping of juvenile offenses in Bangkok, resulting in a mapping of juvenile offenses in Bangkok, applied by GIS programs (10 copies), 30 brochures of risk areas, 10 issues of risk areas in Bangkok, and a map of offenses of children and youth in Bangkok on the Google Earth system. The Metropolitan Police Division can apply this article to create measures to improve the environment and improve the livelihood of the landscape, reduce the area at risk of offenses of children and youth in Bangkok, for police officers under the Metropolitan Police Headquarters, able to be used in planning, controlling, and reducing the crime of 
Table 3: Summary of Environmental Problems and Risk Areas for Juvenile Offenses in Bangkok

\begin{tabular}{|c|c|c|c|c|}
\hline Cases & Police station & The risk point found & Environment & Behavior \\
\hline \multirow{2}{*}{$\begin{array}{c}\text { Cases related to } \\
\text { drugs }\end{array}$} & $\begin{array}{c}\text { Din Daeng Police } \\
\text { Station }\end{array}$ & Flat Number 8 Areas & $\begin{array}{c}\text { It is an 8-stories building, most } \\
\text { of the people living inside. The } \\
\text { flats look like a large family } \\
\text { which makes them quite } \\
\text { crowded. }\end{array}$ & $\begin{array}{l}\text { There is a gathering of } \\
\text { juveniles under the basement } \\
\text { of flats and stairs. Children } \\
\text { and youth will gather to use } \\
\text { drugs. }\end{array}$ \\
\hline & $\begin{array}{l}\text { Thonglor Police } \\
\text { Station }\end{array}$ & $\begin{array}{l}\text { Rimklongpaisingto } \\
\text { Community }\end{array}$ & $\begin{array}{l}\text { It is a rather crowded community } \\
\text { along Saen Saeb Canal. There } \\
\text { are many inhabitants, both } \\
\text { traditional residents and tenants. }\end{array}$ & $\begin{array}{l}\text { Groups of children and youth } \\
\text { living in and out of the area } \\
\text { tend to mix and take drugs in } \\
\text { the homes of the seniors who } \\
\text { solicit }\end{array}$ \\
\hline $\begin{array}{l}\text { Cases related to } \\
\text { property }\end{array}$ & $\begin{array}{l}\text { Din Daeng Police } \\
\text { Station }\end{array}$ & Vibhavadi Rangsit 2 Alley & $\begin{array}{l}\text { Most of the area is dormitory, so } \\
\text { it has a large number of people } \\
\text { living, and during the night time } \\
\text { the alley is completely dark } \\
\text { without any lighting. }\end{array}$ & $\begin{array}{l}\text { Children and juvenile gather } \\
\text { together to cause incidents in } \\
\text { property-related crimes, where } \\
\text { the children and youth will } \\
\text { cause incidents at appropriate } \\
\text { opportunities during the night. }\end{array}$ \\
\hline $\begin{array}{l}\text { Cases related to life } \\
\text { and body }\end{array}$ & $\begin{array}{l}\text { Prawet Police } \\
\text { Station }\end{array}$ & $\begin{array}{l}\text { In front of the lam } \\
\text { Sombat Market bus stop }\end{array}$ & $\begin{array}{l}\text { At the bus stop area, there is a } \\
\text { bush behind which can hide } \\
\text { weapons. }\end{array}$ & $\begin{array}{l}\text { Student groups will prepare to } \\
\text { hide weapons in the area } \\
\text { behind the bus stop in front of } \\
\text { lam Sombat Market. And the } \\
\text { circumstances before the fight, } \\
\text { the institute's symbol is shown. } \\
\text { If the other person does not } \\
\text { mark the institution in } \\
\text { response, it means an } \\
\text { opposing student from another } \\
\text { institution. }\end{array}$ \\
\hline \multirow[t]{2}{*}{$\begin{array}{l}\text { Cases related to } \\
\text { motorcycle racing }\end{array}$} & $\begin{array}{l}\text { Bang Khen Police } \\
\text { Station }\end{array}$ & Thepharak Road & $\begin{array}{l}\text { The area is a new road that can } \\
\text { be used for only about } 1 \text { year } \\
\text { with a long open road. And the } \\
\text { lane is wide }\end{array}$ & $\begin{array}{l}\text { Children and youth meet to } \\
\text { gather to make incendiary } \\
\text { events such as driving cars or } \\
\text { racing motorcycles, etc. Due } \\
\text { to the long open road and } \\
\text { wide lanes, it is possible to } \\
\text { drive the car to test the speed. }\end{array}$ \\
\hline & $\begin{array}{l}\text { Talat Phu Police } \\
\text { Station }\end{array}$ & $\begin{array}{c}\text { Around Pho Nimit BTS } \\
\text { Station }\end{array}$ & $\begin{array}{l}\text { It is an area of a long straight } \\
\text { road. The road surface is evenly } \\
\text { smooth }\end{array}$ & $\begin{array}{l}\text { Children and youth will have } \\
\text { an appointment via Facebook } \\
\text { or Line group. Friends who are } \\
\text { network will gather together for } \\
\text { motorcycle racing on Friday } \\
\text { and Saturday. }\end{array}$ \\
\hline
\end{tabular}

juveniles in the Bangkok Metropolitan Area and publicizing the information to the public to be informed about the children and juvenile offense maps in the
Bangkok area to be more vigilant and avoid traveling to the risky areas. 


\subsection{Mixed Land Use: Most High-Juvenile- Delinquency Areas had Mixed Land Use}

i. Residential buildings with small businesses, such as repair shops and spare parts shops, private rental houses, and public places.

ii. Residential buildings in entertainment areas in which there are various businesses such as massage parlors, pubs and bars.

iii. Foreign tourism attraction areas where goods, food and beverages are laid out on the footpath.

Bangkok has distinct socio-economic diversity. Therefore, the survey of the areas in the Metropolitan Police Divisions 1-9 found that there were slums in all areas, most of which are located along railway lines, on public lands, such as along the canals, or in government-designated low-income apartments.

International travelers move into Bangkok for work, travel or study, and people from other provinces also move into the city for work, with many working in stores, cottage industries or as laborers. Therefore, there are people of diverse backgrounds and economic circumstances living in the same areas, which can result in higher juvenile delinquency.

The fieldwork revealed slum areas, in which there were garbage dumped in public places, graffiti, and poor and insufficient lighting, all of which created the risky conditions for the illegal gathering of juveniles and associated petty crimes.

The results also reveal that the socio-economic degradation in these areas, in which there are lowincome dwellers; entertainment venues such as massage parlors, pubs and bars; and beggars and the homeless, promotes juvenile delinquency, which generally starts with drug abuse in Bangkok. The environmental analysis of the juvenile delinquency risk areas in Bangkok was found to be consistent with Social Disorganization Theory, (Shaw and McKay, 1942) which states that the growth of a country will lead to some disorderly, constantly changing communities (generally migrants and out-of-town residents) that tend to have higher crime rates because of the lack of a constant community control mechanism. Because these areas have populations from other provinces and aliens migrating to the city, the residents are generally poorer and less able to supervise their children because they have to work long hours. Consequently, these areas also tend to have less social control mechanisms to restrict unlawful gatherings of young people. The findings in this study were also consistent with Shaw and McKay, who found that slum areas and retail business areas near the city center, in which there was frequent migration or mainly rental accommodation, were at a higher risk of juvenile delinquency.

The survey found that the juvenile delinquency crime areas in Bangkok tended to be slum areas, secluded and dark alleys, or uncared-for private or public areas, in which the buildings were abandoned and easy to break into to do drugs or other offenses; this was consistent with Wilson and Kelling's Broken Window Theory, which states that if one house has a broken window that is not repaired, the windows of the other houses will be broken, and more offenses will follow as it is assumed that no one in the community cares about the public environment.

It was found that most juvenile offenders tended to commit offenses outside the areas in which they lived to avoid recognition, which was consistent with the findings in Tititampruk's research that found that most offenders committed offenses far from their residences or family members because they were afraid that people close to them would know that they were offenders.

\section{CONCLUSIONS AND RECOMMENDATIONS}

The research study on Environmental Factors and Hot Spot Areas of Juvenile Delinquency in Bangkok was a qualitative study using a qualitative research process consisting of documentary research, in-depth interviews with police officers with operational experience at As well as conducting a survey to apply fundamental data in data analysis using technology, a qualitative data analysis program, and a GIS program to present research results reflecting the environmental problems at risk areas, in which the crime rate for the offenses of children and youth in the Bangkok area is categorized by crimes that have a relatively high rate of occurrence. The results of the research indicated the location, area and environment at risk points, the offense map of children and youth in Bangkok. Including various measures In developing the environment and adjusting the landscape to be livable to reduce the number of areas at risk of offenses of children and youth in Bangkok.

But this study is limited in the study because it collected data from in-depth interviews from police 
officers at the operational level from police stations with environmental problems and risk areas for juvenile offenses and conducting interviews with executive level of police officers from the Superintendent of the Metropolitan Police Division 1-9, which will provide information on the part of the police officer only, so there should be more in-depth interviews in the community groups of the area at risk of offending the offense of children and young people to get ideas on how to improve and guidelines for developing the environment in areas at risk of offenses of children and youth.

In addition, the results of the study reflect the recommendations of research in the policy of the crime prevention and suppression agencies, especially the Royal Thai Police. There should be publicity at risk areas for offenses of children and youth obtained from this research through various media such as Line, Facebook, website of the agencies under the Royal Thai Police, television programs In order for the public to be aware of information and be careful not to travel to the said risk area. In addition, the Royal Thai Police should use the results from this research to develop an Application to map off the offense of children and young people to be accessible and easy to use. Police station management in each area can add risk points to the program by themselves in order to keep the database in the system up to date and consistent with the situation of the crime in each area. In the next research, further research results should be developed by applying the juvenile offense mapping program in the Bangkok area to the actual trial by publicizing the information to the people in the Bangkok area through social media, and should be evaluated on the use of the offense map of children and youth in the said Bangkok area in order to develop the mapping program for the best benefit, and should expand the results of the study to the area of risk in other provinces with high juvenile offense statistics, followed by Bangkok, such as Nakhon Ratchasima, Chonburi Province, Chiang Mai Province to be used to compare the offense patterns of children and youth of the said provinces with Bangkok, how they are similar or different. This will lead to improved environmental development and more effectively reduce the risk of offending the area of children and young people. Recommendations are provided as follows:

Policy Suggestions: The Royal Thai Police's management policy should ensure that there are sufficient police officers in each area to allow for patrols that could intercept risky juvenile behavior and restrain juvenile groups, Moreover, all involved agencies the Royal Thai Police in Bangkok and the local communities, should work together to develop integrated policies focused on modifying and adjusting the environment for safety and security. There should also be a regular review the juvenile delinquency risk areas to lessen the crime incidence.

Operational Suggestions: Co-operation networks among the Royal Thai Police, government agencies, entrepreneurs, schools, and the general public should be developed to establish strong communities that can prevent juvenile delinquency through education and the creation of good social value. Establishments such as gaming lounges should take responsibility and cooperate in solving problems associated with the unlawful assembly of juveniles. Another suggestion is the Royal Thai Police should publicize juvenile delinquency risk areas through various media such as in Line Application and Facebook groups and on websites of the agencies under the Royal Thai Police, and television programs to inform the general public and make them careful and not travel to these risk areas. Finally, the Royal Thai Police should develop a map of juvenile delinquency for each police station; thus, police stations' can add information to their own list of risk areas and regularly update the system.

\section{ACKNOWLEDGEMENTS}

This research received financial support from the National Research Council of Thailand (NRCT) under the Thai Challenge Research Plan: Research for Development and Promotion of Legal Innovation, Forensic Science and Related Databases in the Justice System. The research aimed to solve urgent problems of the juvenile administration and justice administration, Faculty of Forensic Science, Royal Police Cadet Academy.

\section{FUNDING DETAILS}

This work was support by National Research Council of Thailand (NRCT)under Grant (01-2018)

\section{DISCLOSURE STATEMENT}

There is no any conflict interest.

\section{DATA AVAILABILITY STATEMENT}

The data that support the findings of this study are available at National Research Council of Thailand. Restrictions apply to the availability of these data, 
which were used under license for this study. Data are available at www.nrct.go.th with the permission of National Research Council of Thailand.

\section{REFERENCES}

A. Piscitelli, 'Spatial Regression of Juvenile Delinquency: Revisiting Shaw and McKay', 14 International Journal of Criminal Justice Sciences (2019) 132147.DOI:10.5281/zenodo.3712655.

A.Kenwan, Factors Affecting the Offense of Narcotics of Children and Youth, The Juvenile and Family Court, Sakon Nakhon Province. Sukhothai Thammathirat [Open University], Nonthaburi. Retrieved December 25, 2018 from http://dric.nrct.go.th/Search/ShowFulltext/2/294863

B. Se Nakanwagi, 'The role of community education in curbing drug abuse among youth: A case study of Uganda Youth Development Link (UYDEL)' (Kawempe division, Doctoral dissertation, Makerere University).

Braga, A. A., Papachristos, A. V., \& Hureau, D. M. (2012). The effects of hot spots policing on crime. Campbell Systematic Reviews, 8, 1-96.

Brantingham, P., \& Brantingham, P. (Eds.). (1991). Environmental criminology (2nd ed). Prospect Heights, IL: Waveland Press.

C. R. Shaw and H. D McKay. Juvenile Delinquency and Urban Areas: A Study of Rates Delinquents in Relations to Differential Characteristics of Local Communities in American Cities (Chicago, IL: The University of Chicago Press, 1942).

C. R. Shaw and H. D McKay. Juvenile Delinquency and Urban Areas: A Study of Rates Delinquents in Relations to Differential Characteristics of Local Communities in American Cities (Chicago, IL: The University of Chicago Press, 1942).

C.Chidchai, Strategy for preventing motorcycle theft: a case study in one of the southern provinces (Phuket Rajabhat University, 2015).

Cohen, L., \& Felson,M. (1979). Social change and crime rate trends: A routineactivity approach. American Sociological Review, 44(4), 588-605.

Cornish, D., \& Clarke, R. V. (1987). Understanding crime displacement: An application of rational choice theory. Criminology, 25(4), 933-947.

D. Tititampruk, Offender Decision Making: An Assessment of Convicted Burglars in Thailand (Texas State University, 2016)

Department of Juvenile Observation and Protection. (2017). Statistic of Juvenile offenders during 2016-2017. (Internal Official Data).

Department of Observation and Protection and Children and Youth (2018). Information on the Criminal System (CM) Observation Center. Bangkok: Department of Observation and Protection and Children and Youth. Ministry of Justice

Eck, J., \& Weisburd, D. (1995). Crime places in crime theory. In J. Eck, \& D. Weisburd (Eds.), Crime and place (pp. 1-34). Monsey, NY: Criminal Justice Press

G. Schellenberg, C. Lu, C. Schimmele, \& F. Hou, 'The Correlates of Self-Assessed Community Belonging in Canada: Social Capital, Neighborhood Characteristics, and Rootedness', 140(2) Social Indicators Research (2018) 597-618. DOI:10.1007/s11205-017-1783-1.

Green, L. (1996). Policing places with drug problems. Thousand Oaks, CA:Sage Publications

Ibid.

Ibid.

Ibid.

Ibid.
Ibid.

Ibid.

Ibid.

Ibid.

Ibid; K. Wihokmart, 'Self-Concepts in Family and Social Integration among the Recidivist at Juvenile Vocational Training Centres' (Unpublished master's thesis at Thammasat University, Pathum Thani, Thailand, 2009) [in Thai]

J. E. Heinze et al., 'Busy Streets Theory: The Effects of Community-engaged Greening on Violence', 62 American Journal of Community Psychology (2018) 101109.DOI:10.1002/ajcp.12270.

J. Q. Wilson and G. L. Kelling, 'The Police and Neighborhood Safety: Broken Window', 127 Atlantic Monthly (1982) 2938.DOI:10.4324/9781315087863-11

K. Phutaengpetch , Area at risk of car and motorcycle theft in Muang District, Phitsanulok Province.(Unpublished master's thesis at Naresuan University, Phitsanulok, Thailand, 2015) [in Thai]

K.Palaweraphat, Police Officers' Opinions on Motorcycle Race on Public Road in Bangkok, Bangkok (Phranakhon Rajabhat University, 2008).

L. S. Chiew, S. Amerudin, \& Z. M. Yusof, 'A spatial analysis of the relationship between socio-demographic characteristics with Burglar behaviours on burglary crime', in IOP Conference Series: Earth and Environmental Science (IOP Publishing, 2020) 540, at 012050.

M. Levesque, 'Spatial Regression of Juvenile Delinquency: Revising Shaw and McKay', 14(2) International Journal of Criminal Justice Sciences (2020) 132-147. DOI:10.5281/zenodo.3712655/

M. Yeampaisan, Space density crime, A case study of Phra Nakhon Bangkok, study according to the Kernel.Architecture and urban planning (Thammasat University, 2007).

N. Chanrup, 2012. Problem solving of recidivism in drug offenses among youths in the Child and Youth Training Center Area 7 , Chiang Mai Province.(Chiang Mai University: Chiang Mai, 2012) Retrieved December 25, 2018 from http://dric.nrct.go.th/Search/ShowFulltext/2/252616.

N. Purnapanya, 'Factors Affecting Juvenile Delinquency in Respect of Drug Offence: A Case Study of Burirum Province' (Unpublished master's independent study at Rangsit University, Pathum Thani, Thailand.) [in Thai]

N. Suriyachay, Development of a crime map system, a case study of theft in the area of Muang District. Nakhon Pathom Province.(Unpublished master's thesis at Silapakorn University, Bangkok, Thailand, 2010) [in Thai]

N.Songkiatkul, Preventive Measures to Resolve Quarreling Problems of Vocational Students in Bangkok Metropolitan Region (Suan Dusit University, 2017).

N.Wongpanya, Application of GIS to analyze the density of car theft cases in the area of Nakhon Pathom Province(Nakhon Pathom, Thailand:Police Cadet Academy, 2017)

P. Pankaew, Analysis of criminal data using the geographic program. (Unpublished master's thesis at Silapakorn University, Bangkok, Thailand, 2010) [in Thai]

P. Sahaphatthana, Area Analysis Project with high amount of burglary cases (hot spot) in Bangkok area.(Bangkok: Research Fund Office, 2009)

P. Utaphat, Violence Map of Crime in Thailand by Study of the Similarity Order (Mahasarakham Rajabhat University, 2017).

Phutaengpetch , supra note 4.

R. C.Meldrum, G. M. Connolly, J. Flexon, \& R. T. Guerette. Parental low self-control, family environments, and juvenile delinquency. International Journal of Offender Therapy and Comparative Criminology 60, 1623-1644. DOI: 10.1177/0306624X15584907 
S.Treeros, Guidelines for the prevention of drug offense among children and youth: a case study of the Phra Nakhon Si Ayutthaya Child and Youth Training Center (Phranakhon Si Ayutthaya Rajabhat University, 2010).

S.Vidal, D. Prince, C. M.Connell, C. M.Caron, , J. S.Kaufman, \& J. K. Tebes. Maltreatment, family environment, and social risk factors: Determinants of thechild welfare to juvenile justice transition among maltreated children and adolescents. Child Abuse \& Neglect(2017), 63(Suppl. C), 7-18. DOI: 10.1016/j.chiabu.2016.11.013

Sellin, Thorsten. 1938. Culture and Conflict. New York: Social Science Research Council
T. Srithammarong, Assessment of crime risk areas by spatial statistical analysis. (Unpublished master's thesis at Silapakorn University, Bangkok, Thailand, 2016) [in Thai]

Tititampruk, supra note 33.

Tititampruk, supra note 33.

Utaphat, supra note 2.

Utaphat, supra note 2.

Wilson and Kelling, supra note 24.

Wongpanya, supra note 6.

Yeampaisan, supra note 3 .

Srithammarong, supra note 5.

Received on 20-03-2021

Accepted on 19-05-2021

Published on 26-05-2021

https://doi.org/10.6000/1929-4409.2021.10.127

(C) 2021 Ketsil et al.; Licensee Lifescience Global.

This is an open access article licensed under the terms of the Creative Commons Attribution Non-Commercial License (http://creativecommons.org/licenses/by-nc/3.0/) which permits unrestricted, non-commercial use, distribution and reproduction in any medium, provided the work is properly cited. 